\title{
A Systematic Approach To Teaching Critical Thinking Skills To Electrical And Computer Engineering Undergraduates
}

Dr. Karla Conn Welch, University of Louisville, USA Dr. Jeffrey Hieb, University of Louisville, USA

Dr. James Graham, University of Louisville, USA

\begin{abstract}
Coursework that instills patterns of rigorous logical thought has long been a hallmark of the engineering curriculum. However, today's engineering students are expected to exhibit a wider range of thinking capabilities both to satisfy ABET requirements and to prepare the students to become successful practitioners. This paper presents the initial results from a systematic effort to incorporate broader critical thinking instruction and assessment into electrical and computer engineering education as part of a university-wide quality enhancement program. All incoming freshmen are given explicit and implicit instruction in critical thinking in ENGR 100: Introduction to Engineering and other engineering fundamentals courses, using the Paul-Elder framework of critical thinking to define and operationalize critical thinking. This critical thinking foundation is reinforced later in the disciplinary courses so that students integrate critical thinking with the basic principles and practices of engineering. In the Electrical and Computer Engineering (ECE) program, at the sophomore level, students use critical thinking skills which were developed during their engineering fundamentals courses, to analyze requirements and constraints which would apply in real-world design projects. At the junior level, similar use of critical thinking is applied in an introductory computing methods course; and at the senior level, critical thinking skills are again strengthened and assessed in the capstone design course and in the professional issues and current topics seminar. The latter course emphasizes understanding of professional ethics and current topics in electrical and computer engineering. Initial data from this pilot implementation indicates statistically significant improvement in critical thinking skills in ECE students who have progressed through this sequence, and as a side benefit, it appears that writing skills also improve.
\end{abstract}

Keywords: Critical Thinking; Engineering Education; ABET

\section{INTRODUCTION}

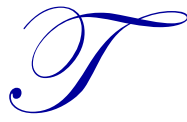

he Southern Association of Colleges and Schools (SACS) requires all accredited schools to design and implement a Quality Enhancement Program (QEP). In 2007 the University of Louisville adopted as its QEP the requirement that all schools within the university, including the School of Engineering, develop and implement an ongoing and school-wide program to "improving the critical thinking skills of undergraduate students and to more effectively prepare them to contribute to society" (Ideas to Action [i2a], 2007, p. $5)$.

The ideas-to-action (i2a) QEP, with its focus on enhancing critical thinking was embraced by the faculty of the J. B. Speed School of Engineering and by the faculty of the Department of Electrical and Computer Engineering (ECE). Recent engineering education research results suggest that engineering students can benefit from improved 
critical thinking instruction (Bays \& Ralston, 2015; Cooney, Alfrey, \& Owens, 2008). At the present, however, there is a lack of explicit critical thinking outcomes and content in course syllabi in most curricula (Niewoehner, n.d.; Paul, Elder, \& Bartell, 1997). For example, Cooney et al. (2008) present survey results that showed a disconnect between the amount of critical thinking experience engineering and technology faculty believed they were providing to students and the amount of critical thinking experience students perceived they were receiving.

Furthermore, critical thinking supports various Accreditation Board for Engineering and Technology (ABET) program outcomes from the (a) through (k) skill set required for all graduating engineering students. Specifically, critical thinking skills support engineering students developing the "broad education necessary to understand the impact of engineering solutions in a global, economic, environmental, and societal context" (i.e., skill set (h)) (ABET, 2014, p. 3). Critical thinking also supports the ABET program outcome "a recognition of the need for, and ability to engage in, life-long learning," and it is an essential component of "the ability to identify, formulate, and solve engineering problems" (i.e., skill sets (i) and (e), respectively) (ABET, 2014, p. 3). Other schools have reached similar conclusions (Nelson, 2001).

The following section of this paper describes the J. B. Speed School of Engineering's response to the i2a initiative, and briefly describes the integration of that response into fundamental courses common to all engineering students. The remaining sections of the paper present how the ECE department incorporated the university's i2a initiative into discipline-specific courses. This pilot implementation is presented as an informative reference for engineering educators, ECE professors in particular, as a means to explicitly introduce critical thinking in the classroom. Evaluation of this initial effort is provided, on an individual course basis, in qualitative conclusions from instructors and quantitative assessment of students' work. Specifically, section three discusses the ECE department's plans to emphasize critical thinking in the sophomore course ECE 220: Network Analysis 1, the junior level course ECE 322: Introduction to ECE Computing Tools, and in the senior course ECE 496: Professional Issues and Current Topics Seminar. Section four discusses preliminary critical thinking assessment conducted ECE 496. Concluding remarks are presented in the final section.

\section{INTRODUCING CRITICIAL THINKING INTO THE ENGINEERING CURRICULUM}

In response to the university's i2a initiative, the J. B. Speed School of Engineering at the University of Louisville has developed a multi-leveled critical thinking program that begins with the school's freshman program: ENGR 100: Introduction to Engineering, and goes on to include sophomore, junior, and senior courses, co-op reports from semester-long cooperative education experiences in professional engineering companies, and undergraduate engineering capstone projects. A graphical representation of the current plan is shown in figure 1. This paper describes the components relevant to ENGR 100, ENGR 205: Differential Equations for Engineers, and three discipline-specific courses. This illustration is a top-level view of the initiative. How the implementation within the ECE department plays a role in the overall initiative is illustrated in figure 1 by the courses administered by the department, namely discipline-specific courses, co-op experience, and capstone projects; and this role is also described in the Conclusions section. At points in the curriculum, critical thinking is explicitly incorporated into specific courses through instruction, activities, and assignments. More advanced and discipline-specific critical thinking is characteristic of the upper level courses and capstone projects. General critical thinking, focused on ensuring students are able to clearly define critical thinking, recognize critical thinking, and applying critical thinking to simpler and well-defined problems is the focus in lower level courses. While there are specific courses targeted for critical thinking instruction and assessment, it is the intention that most courses become more intentional in their treatment of critical thinking. A primary way in which this will happen is through the use of a common language for critical thinking. To facilitate this, the Paul-Elder framework for critical thinking (Paul \& Elder, 2009) has been adopted as the model for critical thinking. Instructors can use the framework in their lecture, in their assignments, and in their assessments. In fact, a holistic rubric for critical thinking, based on the Paul-Elder framework, has been developed and is given in Appendix A. An instructor's incorporation of the Paul-Elder framework as a common language will allow students to readily recognize critical thinking, without explicit mention on the part of the instructor. 
Figure 1. J. B. Speed School of Engineering's critical thinking, abbreviated CT in figure, education plan.

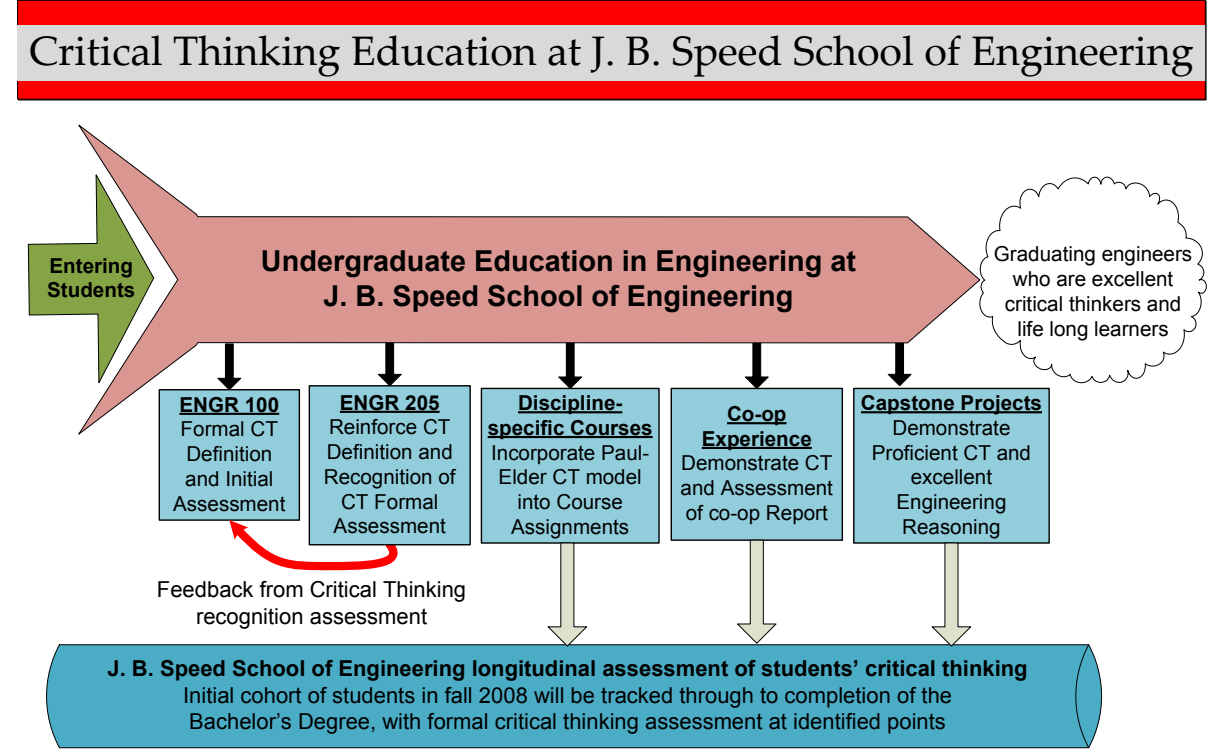

\section{The Paul-Elder Framework for Critical Thinking}

The Paul-Elder framework constructs critical thinking into the Standards, the Elements, and Intellectual Traits; and imposes the following relationship on that decomposition: the Standards are applied to the Elements as we learn to develop Intellectual Traits (Paul \& Elder, 2009). The purpose of the framework is to aide in the analysis and evaluation of thought and to provide a common vocabulary for critical thinking. A benefit of this framework is that it is a discipline neutral, general framework for critical thinking. The framework is shown in figure 2.

For students and instructors the framework provides a common language for defining and operationalizing critical thinking by defining eight Elements of thought which capture how critical thinking examines, analyzes, and reflects on intellectual work. These eight Elements lead to eight categories of questions present, to some degree, in all critical thinking: (1) what is the Purpose?, (2) what is the Point of View?, (3) what are the Assumptions?, (4) what are the Implications?, (5) what Information is needed?, (6) what Inferences are being made?, (7) what is the most fundamental Concept?, and (8) what is the Question that is being answered? The intellectual Standards describe the criteria used to evaluate the quality of the critical thinking (see also Appendix A). For example: the thinking has a clear purpose or makes relevant assumptions. The Intellectual Traits are the characteristics associated with a mature critical thinker and are developed by individuals over time. The intent is that students will develop and exhibit these traits as they proceed through the curriculum. In other words, in time, students will develop metacognitive abilities in regards to critical thinking. For more information on the Paul-Elder framework for critical thinking the reader is referred to guides from Paul and Elder (2009) and from Paul, Niewoehner, and Elder (2006). The J. B. Speed School of Engineering is working towards making these guides universally available to its students. 
Figure 2. The Paul-Elder framework for critical thinking (Paul \& Elder, 2009, p. 19).

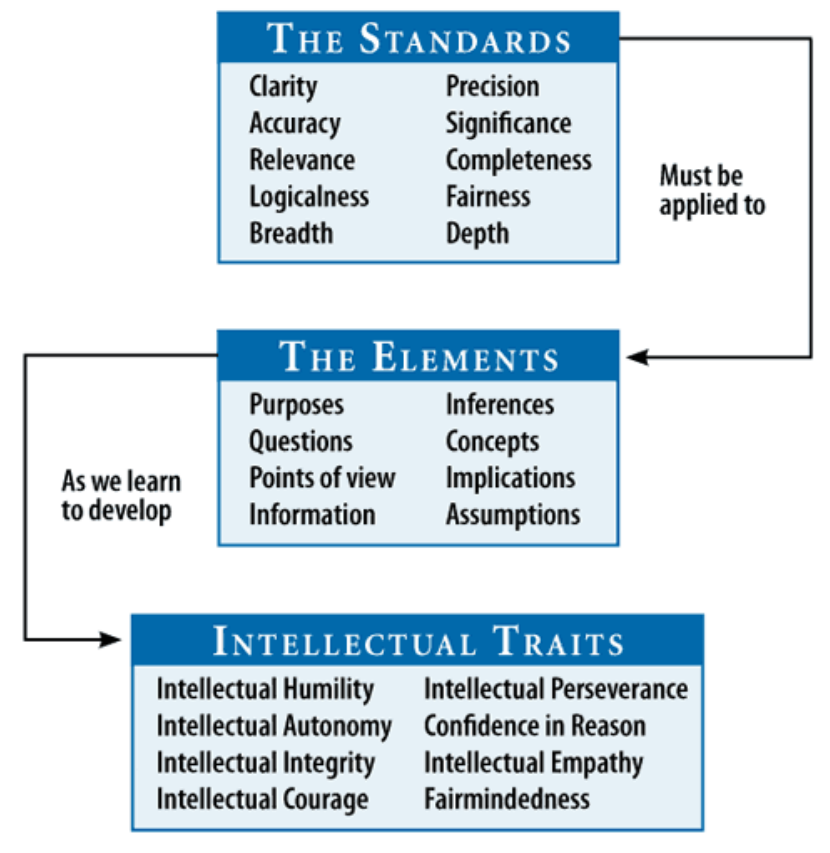

\section{Critical Thinking Instruction in Engineering Fundamentals Courses}

Incoming engineering students may have misconceptions about critical thinking, may find it difficult to define critical thinking, and their critical thinking skills are likely to be at a variety of different levels. To address this, critical thinking is made an explicit component in ENGR 100 and ENGR 205. These courses are common to all engineering students, and should be completed by the end of the fall semester of the second year. Therefore, introduction to the university's common language on critical thinking is comprehensive and timely. The potential for success is promoted when an education plan (refer to figure 1) is designed such that students learn how to think critically early in their degree program (O'Brien-McElwee, 2013), feedback is provided throughout their degree, and critical thinking is assessed throughout their degree; thus, leading to students who can demonstrate critical thinking in upper-level courses and later in work and life (Barr \& Tagg, 1995). The critical thinking instruction in these lower-level courses includes explicit instruction of the Paul-Elder framework, explicit and overt modeling of critical thinking, and specific critical thinking activities.

A review by Cooney and colleagues (2008) of recent educational research literature identified two distinct themes when it came to developing critical thinking skills in engineering and technology students. Those two themes are writing for reflection and problem-based learning. Writing for reflection promotes critical thinking by having students digest given information, analyze the content and the thinking, think about their own thinking, and then articulate their thoughts and/or value judgments. Problem solving is a central component in engineering and technology, and problem-based learning is a natural extension of the problem solving common in engineering, and creates opportunities for students to "do" critical thinking. These two approaches have served as inspiration for the development of critical thinking instruction in the engineering fundamental courses, though other more direct approaches are also used.

In ENGR 100, students are given explicit instruction on the Paul-Elder framework during a traditional lecture based class meeting. The Elements and Standards of critical thought, shown in figure 2, are presented, explained, and demonstrated to the class. Then, following the lecture, students go to their respective breakout rooms (about 30 students per room). During the breakout part of the class, there is a review of the Elements and the Standards. Then students work individually on four or five problems that require critical thinking (including two questions that were introduced during the lecture portion of the class). These questions include word problems that involve setting up algebraic equations and the NASA moon survival problem (Hall \& Watson, 1970; Shurdington 
Scouts Resource, n.d.). As a conclusion, students are asked to discuss which Elements of critical thought were important in solving the problems, an oral form of writing for reflection.

Critical thinking instruction is also incorporated into the case studies that are used in the ENGR 100 course. The case studies are failure case studies from engineering. The major failure case that is examined in the class is the Hyatt Regency Walkway Collapse ("Hyatt Regency," 2006; Pfrang \& Marshall, 1982), in which 114 people died due to a structural failure, and which lead to number of principals losing their engineering licenses. In their presentation of case study material, instructors model critical thinking to students. They use the Elements and Standards from the Paul-Elder framework (without making explicit reference to the framework) to help students fortify their understanding of critical thinking and become aware of the fundamental relationship between critical thinking and engineering. During case study activities, students are provided an opportunity to evaluate both their own and others' thinking to determine if it incorporates the Elements and Standards of critical thought. For example, students are advised to review their papers to ensure they contain the Elements of critical thought and that all information, analysis, and conclusions are presented clearly and logically and that all questions are completely answered. When presenting their own case study analysis, instructors use the Elements and the Standards from the Paul-Elder framework to emphasize the parts of their analysis that exemplify critical thinking. Finally, students are encouraged to compare their critical thinking to the critical thinking of an engineer or group of engineers whose thinking they have become familiar with during the case study. The case studies thereby reinforce the implicit critical thinking elements of the course; giving the students a chance to see and implement critical thinking as they work on the case study assignments and activities. A more detailed description of the critical thinking instruction in ENGR 100 is provided by Lewis, Hieb, and Wheatley (2009).

ENGR 205 is a course typically taken in the fall of the second year. It is a required course for all engineering majors. Beginning in the fall of 2009 this course began including specific critical thinking activities. The Paul-Elder framework is incorporated into the course material on mathematical modeling. The Paul-Elder framework provides an excellent context for the activity and evaluation of developing mathematical models, and the Elements and the Standards are found throughout the text's discussion of mathematical modeling. During lectures where the differential equations for spring mass systems, electrical circuits and mixing problems are developed, the language of the Paul-Elder framework is used to highlight the critical thinking present in the development of the models. Finally, at the end of the course, students are asked to do a critical thinking writing for reflection activity related to methods for solving differential equations. This writing for reflection artifact is used as part of an assessment of the progress individual engineering students are making in developing good critical thinking skills.

Also during the second year, critical thinking instruction and assessment move into specific departments. Each department is working on selecting upper level courses in which to infuse critical thinking, and assuring that critical thinking is explicitly a part of the assessment of capstone projects. The following section discusses how critical thinking instruction and assessment has been implemented in the ECE department.

\section{CRITICAL THINKING IN DISCIPLINE-SPECIFIC ECE COURSES}

In planning how the ECE department would meet the requirements of the university-wide QEP, there was unanimous faculty agreement that critical thinking is an important requirement to be successful within the electrical engineering profession. As previously-mentioned, the faculty concur that ABET program outcomes would be supported by explicit instruction of critical thinking in the classroom. Additionally, this decision aligns with informal accounts from employers during meetings with the ECE department's board of advisors, and faculty are familiar with the literature on employers noting a lack of critical thinking as a key shortcoming of engineering graduates (ACNielsen Research Services, 2000; Nelson, 2001). In an effort to help students become better critical thinkers and appreciate the importance of its practice throughout their education and careers, critical thinking and engineering reasoning was implemented in several key courses throughout the ECE curriculum. At the current time critical thinking instruction is formally incorporated into one sophomore level course, one junior level course, and two senior level courses, while informal critical thinking instruction is a part of most of the remaining courses in the undergraduate ECE curriculum. At present, the assessment of this activity has not been incorporated into the broader ABET assessment activities of the ECE department. Critical thinking obviously impacts many of the required eleven program outcomes, and could be incorporated into the assessment of one or more of them. 
At the sophomore level, the ECE 220 course was selected for critical thinking emphasis. Co-author Welch introduced critical thinking methods into ECE 220 over three semesters with promising results in better student performance. This course builds the foundation for more advanced circuit analysis, so creating an environment where students think critically about the material should lead to deeper understanding of circuits' concepts as students progress through the discipline. Therefore, ECE 220 is a key course in the curriculum for the ECE department to implement critical thinking techniques and evaluate the outcomes to guide best practices in the future.

The introduction of critical thinking into ECE 220 started with one exercise in the spring of 2010 and gradually built in more critical thinking exercises each semester. Each semester, lesson 4 (Node Voltage Method for solving electrical circuits) and lesson 5 (Mesh Current Method for solving electrical circuits) have been the focus for critical thinking exercises. These lessons are similar enough that introducing a new learning method in one could be used to compare to the other, as opposed to comparing dissimilar topics. In the Spring 2010 semester, during class the students completed a one-page written SEE-I (Nosich, 2012) on lesson 5. The prompts in the four short-answer sections given to the students are listed below. A SEE-I asks students to briefly:

- $\quad$ State the definition of a topic (e.g., "The Mesh Current Method is..."),

- $\quad$ Elaborate on that definition (e.g., "To elaborate,..." or "In other words, the Mesh Current Method is..."),

- $\quad$ give an Example of the topic (e.g., "For example, in the circuit below, the mesh currents are..."),

- $\quad$ and Illustrate how the topic is analogous to a related concept (e.g., "Another way to think of the Mesh

Current Method is..." or "The Mesh Current Method reminds me of...").

The SEE-I process originated with Paul and Elder (2005) and was refined by Nosich (2012). Nosich (2012) recommends, and assigns in his own classes, students complete a SEE-I when preparing for an exam, when writing a paper, as homework, and as test questions. The SEE-I is designed to clarify a topic - first by clarifying it in the student's own mind and then by communicating clearly to others. Critical thinking stems from the Socratic Method of probing questions. Furthermore, asking questions is a means to make things clearer, and a SEE-I facilitates gaining clarity on a topic (Nosich, 2012).

The SEE-I goes beyond the ability to define a topic and can be used to assess deeper understanding of a topic. SEE-Is can be used when writing the body of a paper; i.e., stating your first main point, elaborating on it, giving an example, and illustrating the point. The Paul-Elder critical thinking framework can be woven into a SEEI, such as choosing an example based on your consideration of different Points of View. SEE-Is can be used when writing for reflection and during problem-based learning - the two themes Cooney and colleagues (2008) highlight as important ways to develop critical thinking in engineering disciplines. In ECE 220, students worked through the SEE-I on the topic of "the Mesh Current Method" with their homework partner at the end of the lecture instruction for the lesson. The SEE-I exercises were subsequently discussed in class using the Paul-Elder framework (e.g., identifying the significant concepts of a topic).

The SEE-I provides a way to analyze what foundational information students are using to base their equations to represent a circuit. For example, in Spring 2010, only a few student groups mentioned in their elaboration on Mesh Current "resistor in a shared branch between meshes," but defining whether an electrical component like a resistor is shared or not between meshes is a pivotal piece of evidence with which to formulate the equation to represent the circuit. Without critical thinking exercises like the SEE-I, it can be difficult for the instructor to tease out from an incorrect equation what concept or underlying information the students are misunderstanding or not identifying as significant. Significance is one of the intellectual Standards in the PaulElder framework of critical thinking (Paul \& Elder, 2009). Therefore, incorporating more exercises that ask students to analyze a problem through critical thinking, such as the SEE-I, and discussion of the Significant factors of a problem, delineating the Logic of their solution method, and evaluating the Accuracy of their answer; will highlight their misconceptions which will direct the instruction and presumably increase their understanding.

A second SEE-I for lesson 4 was introduced in Fall 2010, and the lesson 5 SEE-I was kept as before. Standard quizzes were given to check student mastery of the circuits' concepts covered in these lessons. A twosample $t$-test was performed to test the null hypothesis that the means were equal between different semesters in 
which the quizzes were given. The quiz averages on each of these lessons increased significantly between the Spring 2010 semester $(\mathrm{N}=15)$ and the Fall 2010 semester $(\mathrm{N}=22)$, from $61.73 \%$ to $82.73 \%$ for lesson $4(p<0.001$, significant) and from $69.73 \%$ to $86.14 \%$ for lesson 5 ( $p<0.001$, significant). The SEE-I was kept for the Fall 2011 semester $(\mathrm{N}=32)$, and quiz scores remained high (i.e., lesson 4 mean $=78.59 \%$, lesson 5 mean $=87.81 \%$ ). When comparing mean quiz scores by a two-sample $t$-test between Fall 2010 and Fall 2011, for both lesson 4 and lesson 5, scores were statistically the same ( $p=0.461$ and $p=0.650$, respectively).

For the Spring 2012 semester, a critical thinking focus early-on in the semester was added. During the first week of this class students viewed a video taken on graduation day at MIT's campus (Private Universe Project, 1989). In the video recent engineering graduates were asked if they thought they could turn on a light bulb using a battery and wire. The scene plays out that although all students proclaimed confidently that they could do this task, ultimately they could not turn the bulb on; furthermore, they could not explain why their bulb-wire-battery assemblies did not work. For example, some graduates in the video only connected the wire between the negative side of the battery and one side of the bulb's filament but kept the bulb away from the positive side of the battery, thus not completing the circuit. After the video co-author Welch asked students in ECE 220 what skills the MIT engineering graduates may be lacking that would have improved their performance in the light bulb task. They were given a list of skills that graduates should acquire on their way to earning a degree. The poll results show students believed better critical-thinking skills (most-popular choice) and application skills (second-most-popular choice) would have been the most-beneficial for the students in the video.

For lesson two in ECE 220, students were asked to consider the Point of View, one of the Elements of thought (Paul \& Elder, 2009), of a manufacturer of resistors used in electrical devices. One of the homework problems asked students to design a specific configuration of an amount of resistance, price the cost of their design with an online supplier, and then use critical thinking to answer why a manufacturer would stock some values of resistors but not every imaginable value. All students were able to connect that since resistors can be combined to provide different amounts of resistance, stocking a few general values that can be used in different combinations in many devices is more efficient than stocking a vast variety of specific values that have more limited applicability. Students unanimously understood that manufacturers must deal with inventory constraints and therefore design engineers must deal with cost constraints related to the availability of components (i.e., a secondary focus of the course), which are important concepts of how engineering design relates to factors beyond the electrical functions of a circuit (i.e., the main focus of the course).

At the junior level, critical thinking is taught and evaluated in the class ECE 322, which focuses on teaching the mathematical tool, MATLAB ${ }^{T M}$. The approach to teaching critical thinking skills used in this course is to provide an abbreviated review, using the same language and pedagogy used in previous semesters, at the time that function calls are covered in the course. Then homework assignments are given that require that a help file be written that describe the Purpose of any function they write. The students are specifically told not to simply echo the sequence of computational steps required to carry out the function, but to describe the Purpose of the function call. The help files are to be written from a Point of View of a person who is not taking the course, and thus has no knowledge of the homework assignment.

For example, in the Summer 2012 semester, the students were asked to create a function in MATLAB that will output a spectrogram (i.e., a 2-D plot of a Fourier Transform versus time) when given a song's filename as input. They were also required to include a help file, consisting of the following items: (a) Title, (b) Usage syntax, (c) General description of the function, including expected output, (d) Detailed description of the function (including mathematical basis), and (e) Examples of usage. The Paul-Elder Standards of Clarity and Accuracy are present in all portions of the help file. Precision and Completeness are present in parts $b, d$, and e. Significance is present in parts $\mathrm{c}$ and e. Breadth and Depth are present in parts $\mathrm{c}$ and $\mathrm{d}$, as the description must have sufficient depth to permit a thorough understanding of the function, and also contain enough breadth that a user could potentially see how the function could be applicable for other people to solve their own problems.

At the senior level, critical thinking skills will again be strengthened and assessed in ECE 496. This course emphasizes understanding of professional ethics and current topics in electrical and computer engineering. ECE 496 is of particular interest because it is in many ways the ideal place to perform an overall assessment of the critical 
thinking skills of electrical and computer engineering undergraduates. Some additional detail about the critical thinking instruction and assessment in this course are presented in the next section.

\section{CRITICAL THINKING ASSESSMENT IN ECE 496}

Critical thinking instruction has been incorporated into the course body of ECE 496 for the past two years. Two of the authors who participated in the University of Louisville's Faculty Learning Community on i2a Critical Thinking have taught the class during recent semesters. This class is an ideal locus for an assessment of critical thinking skills of seniors in the electrical and computer engineering program. All ECE seniors are required to take the course and students are not permitted to take it until they have reached senior (i.e., fourth year) status. The course material lends itself well to further practice of critical thinking by students, as they are asked to read quite a bit about current topics in electrical and computer engineering from IEEE Spectrum and other sources, and produce a paper on a current electrical or computer technology of their choice. This requires critical reading, evaluation of sources, evaluation of possible biases or other hidden agendas, and the ability to formulate and support their conclusions in a concise and cogent form. Likewise they are asked to investigate an ethical case study, where failure to observe one or more of the precepts of the ethical practice resulted in a catastrophe. Again careful reading and reasoning skills are required.

Each class section in 2012 has had review of critical thinking methodologies using The Miniature Guide to Critical Thinking Concepts \& Tools (Paul \& Elder, 2009) as well as in-class activities, and a writing assignment. The writing assignment required students to identify and analyze the major themes and soundness of reasoning using the Elements of thought from the Paul-Elder framework, including Purpose, Question, Information, Concepts, Assumptions, Inferences, Point of View, and Implications. The writing assignment was scored on the four-point critical thinking rubric (Appendix A) and also on a six-point writing rubric, emphasizing writing mechanics.

Scores from students who took the class in $2012(\mathrm{~N}=21)$, who had been exposed to critical thinking concepts, were compared with a two-sample $t$-test to a group of student papers $(\mathrm{N}=23)$ from ECE 496 classes in 2009. All papers were graded using the same critical thinking and writing rubrics. Out of the four-point range, the mean of the critical thinking scores was 3.00 in 2009 and 3.57 in 2012. Out of the six-point range, the mean of the writing scores was 4.41 in 2009 and 4.74 in 2012.

Based on a two-sample $t$-test, the mean critical thinking scores for the students in 2012 were statistically significantly better than the critical thinking scores of the 2009 cohort $(p<0.01$, significant), yielding support to our observation of better critical thinking abilities for the students who have had systematic exposure to critical thinking instruction throughout their engineering studies, from freshman to senior years. Equally encouraging was the increase in writing scores, which a two-sample $t$-test showed moderate improvement between the 2012 cohort and 2009 cohort in writing scores $(p=0.132)$. Written communications ability has been a long-standing area of concern for engineering students (Kimel \& Monsees, 1979; Pinelli, Barclay, Keene, Kennedy, \& Hecht, 1995), and it is encouraging to see this improved performance in a group of electrical and computer engineering seniors!

\section{CONCLUSIONS}

Most engineering professors think that they inherently teach logical thought and critical reasoning to their students. Certainly careful, logical reasoning is one of the hallmarks of our profession. Students who can memorize formulas and produce numerical problems on our in-class examinations often lack the skills to carefully analyze a problem, identify the key requirements and constraints in real world problems. The University of Louisville is currently engaged in a multi-year experiment to see if we can enhance the critical thinking skills of students and improve their abilities to apply what they learn to real-world problems. The student papers assigned and assessed from ECE 496 were used as writing artifacts in the longitudinal study. The study across the J. B. Speed School of Engineering publishes aggregate data on assessment of larger groups of students. This work takes a more-detailed look at ECE's implementation, including descriptions of specific assignments used in the curriculum to support the more-expansive implementation of critical thinking methods. Exposure to critical thinking assignments, using the Paul-Elder framework, in discipline-specific courses is part of the intervention students undergo in the educational plan described at the level of the longitudinal study. This work also provides results at the classroom level, 
providing information to how to implement and what to expect on an individual course basis. For educators and administrators, both this paper and the J. B. Speed School of Engineering's paper on the longitudinal study (Bays \& Ralston, 2015) are recommended.

The results, both anecdotal and quantitative, from the efforts to date have led the authors to conclude that continuing to adopt critical thinking techniques within the instruction for existing engineering classes will be beneficial both from an instructor's perspective - to provide insight into areas of misunderstanding - and for the student's perspective - to provide them with opportunities to re-examine and deepen their understanding of the material. This paper presents a snapshot of this endeavor as we attempt to apply this new approach to the education of electrical and computer engineering students. It is clearly a work in progress, but initial results are promising.

\section{AUTHOR BIOGRAPHIES}

Dr. Karla Conn Welch received the B.S. degree in Electrical and Computer Engineering from the University of Kentucky in 2003 and her PhD in Electrical Engineering and Computer Science from Vanderbilt University in 2009. She is currently an Assistant Professor with the Department of Electrical and Computer Engineering at the University of Louisville. Her research interests include human-machine interaction, affective computing, robotics, and engineering education. She is a member of ASEE (American Society for Engineering Education), IEEE (Institute of Electrical and Electronics Engineers), AAAC (Association for the Advancement of Affective Computing), and SWE (Society of Women Engineers).

Dr. Jeffrey Hieb is an Associate Professor in the Department of Engineering Fundamentals at the University of Louisville. Jeff completed his Ph.D. in Computer Science Engineering at the University of Louisville's J. B. Speed School of Engineering in 2008. Since completing his degree, Jeff has been teaching engineering mathematics courses to first and second year engineering students. The focus of his research has been on high assurance security solutions for industrial control system field devices, and in engineering education and educational technology.

Dr. James Graham is Professor Emeritus at the University of Louisville, having served almost thirty years as a faculty member and seven years as Chairman of the Dept. of Electrical and Computer Engineering. He received his BSEE from the Rose-Hulman Institute of Technology in 1972 and his MS and PhD degrees in Electrical Engineering from Purdue University in 1978 and 1980 respectively. His research interests include robotics, intelligent systems and cyber-security of industrial systems. He is a Senior Member of the IEEE.

\section{REFERENCES}

Accreditation Board for Engineering and Technology. (2014). Criteria for accrediting engineering programs: effective for reviews during the 2015-2016 accreditation cycle. Baltimore, MD: ABET Engineering Accreditation Commission. Retrieved from http://www.abet.org/wp-content/uploads/2015/05/E001-15-16EAC-Criteria-03-10-15.pdf

ACNielsen Research Services. (2000). Employer satisfaction with graduate skills: research report. Canberra, Australia: Department of Employment, Education, Training and Youth Affairs.

Barr, R. B., \& Tagg, J. (1995). From teaching to learning-a new paradigm for undergraduate education. Change, 27(6), 13-25.

Bays, C., \& Ralston, P. A. S. (2015, in press). Critical thinking development in undergraduate engineering students from freshman through senior year: a 3-cohort longitudinal study. American Journal of Engineering Education.

Cooney, E., Alfrey, K., \& Owens, S. (2008, 22-25 June). Critical thinking in engineering and technology education: a review. Paper presented at the 2008 American Society for Engineering Education Annual Conference and Exhibition, Pittsburgh, PA.

Hall, J., \& Watson, W. H. (1970). The effects of a normative intervention on group decision-making performance. Human Relations, 23(4), 299-317.

Hyatt Regency walkway collapse. (2006). Retrieved from http://www.engineering.com/Library/ArticlesPage/tabid/85/ArticleID/175/Hyatt-Regency-WalkwayCollapse.aspx 
Ideas to Action. (2007). Ideas to action: using critical thinking to foster student learning and community engagement. Retrieved from http://louisville.edu/ideastoaction/-/files/final-report.pdf

Kimel, W. R., \& Monsees, M. E. (1979). Engineering graduates: how good are they? Engineering Education, 70(2), $210-212$.

Lewis, J. E., Hieb, J. L., \& Wheatley, D. (2009, 14-17 June). Explicit teaching of critical thinking in "Introduction to Engineering." Paper presented at the 2009 American Society for Engineering Education Annual Conference Exposition, Austin, TX.

Nelson, S. (2001, 10-13 October). Impact of technology on individuals and society: a critical thinking and lifelong learning class for engineering students. Paper presented at the 31st ASEE/IEEE Frontiers in Education Conference, Reno, NV.

Niewoehner, R. J. (n.d.). Applied disciplines: a critical thinking model for engineering. Retrieved from http://www.criticalthinking.org/pages/applied-disciplines-a-critical-thinking-model-for-engineerin/578

Nosich, G. M. (2012). Learning to think things through: a guide to critical thinking across the curriculum. Upper Saddle River, NJ: Pearson Prentice Hall.

O’Brien-McElwee, R. (2013). Teaching and advising first-year students. Observer, 26(4).

Paul, R. W. \& Elder, L. (2005). Critical thinking: tools for taking charge of your learning and your life (2nd ed.). Upper Saddle River, NJ: Pearson Prentice Hall.

Paul, R. W. \& Elder, L. (2009). The miniature guide to critical thinking concepts \& tools (6th ed.). Dillon Beach, CA: The Foundation for Critical Thinking.

Paul, R. W., Elder, L., \& Bartell, T. (1997). California teacher preparation for instruction in critical thinking: research findings and policy recommendations from a study of 38 public universities and 28 private universities to determine faculty emphasis on critical thinking in instruction. Sacramento, CA: California Commission for Teacher Credentialing (ERIC Document Reproduction Service No. ED437379).

Paul, R. W., Niewoehner, R. J., \& Elder, L. (2006). The thinker's guide to engineering reasoning (2nd ed.). Dillon Beach, CA: The Foundation for Critical Thinking.

Pfrang, E. O., \& Marshall, R. (1982). Collapse of the Kansas City Hyatt Regency walkways. Civil Engineering: The Magazine of the American Society of Civil Engineers, 52(7), 65-69.

Pinelli, T. E., Barclay, R. O., Keene, M. L., Kennedy, J. M., \& Hecht, L. F. (1995). From student to entry-level professional: examining the role of language and written communications in the reacculturation of aerospace engineering students. Technical Communication, 42, 492-503.

Private Universe Project, (1989). A private universe [Videotape]. Cambridge, MA: Harvard-Smithsonian Center for Astrophysics.

Shurdington Scouts Resource. (n.d.). NASA exercise: survival on the Moon. Retrieved from http://www.shurdington.org/Downloads/NASA\%20Exercise.pdf 


\section{APPENDIX A}

University of Louisville

J. B. Speed School of Engineering

Holistic Critical Thinking Rubric

Consistently does all or most of the following:

\begin{tabular}{|l|l|}
\hline \multicolumn{1}{|c|}{ Score } & \multicolumn{1}{c|}{ Rubric Description } \\
\hline $\mathbf{4}$ & $\begin{array}{l}\text { Clearly identifies the purpose including all complexities of relevant questions. } \\
\text { Accurate, complete information that is supported by relevant evidence. } \\
\text { Complete, fair presentation of all relevant assumptions and points of view. } \\
\text { Clearly articulates significant, logical implications and consequences based on relevant evidence. }\end{array}$ \\
\hline $\mathbf{3}$ & $\begin{array}{l}\text { Clearly identifies the purpose including some complexities of relevant questions. } \\
\text { Accurate, mostly complete information that is supported by evidence. } \\
\text { Complete, fair presentation of some relevant assumptions and points of view. } \\
\text { Clearly articulates some implications and consequences based on evidence. }\end{array}$ \\
\hline $\mathbf{2}$ & $\begin{array}{l}\text { Identifies the purpose including irrelevant and/or insufficient questions. } \\
\text { Accurate but incomplete information that is not supported by evidence. } \\
\text { Simplistic presentation that ignores relevant assumptions and points of view. } \\
\text { Articulates insignificant or illogical implications and consequences that are not supported by evidence. }\end{array}$ \\
\hline $\mathbf{1}$ & $\begin{array}{l}\text { Unclear purpose that does not includes questions. } \\
\text { Inaccurate, incomplete information that is not supported by evidence. } \\
\text { Incomplete presentation that ignores relevant assumptions and points of view. } \\
\text { Fails to recognize or generates invalid implications and consequences based on irrelevant evidence. }\end{array}$ \\
\hline
\end{tabular}




\section{NOTES}

